\title{
Comparison of Rate of Infection during Hydroxyapatite and Allogenic Bone Graft Used In Jaw Cyst: A Randomized Clinical Trial
}

\author{
Showkat Mamun ${ }^{1}$, Ismat Ara Haider ${ }^{2}$, Nasiruddin ${ }^{3}$, Tarin Rahman ${ }^{4}$, Sheikh Mohammad Jahidul \\ Islam $^{5}$, Farah Diba ${ }^{6}$
}

\begin{abstract}
${ }^{1}$ Assistant Professor, Department of Oral and Maxillofacial Surgery, Dhaka Dental College \& Hospital, Dhaka, Bangladesh; ${ }^{2}$ Professor \& Head, Department of Oral and Maxillofacial Surgery, Dhaka Dental College \& Hospital, Dhaka, Bangladesh; ${ }^{3}$ Professor \& Head, Department of Oral and Maxillofacial Surgery, Shaheed Suhrawardy Medical College \& Hospital, Dhaka, Bangladesh; ${ }^{4}$ Associate Professor, Department of Oral and Maxillofacial Surgery, Dhaka Dental College \& Hospital, Dhaka, Bangladesh; ${ }^{5}$ Assistant Professor, Department of Oral and Maxillofacial Surgery, Dhaka Dental College \& Hospital, Dhaka, Bangladesh; ${ }^{6}$ Junior Consultant (Paediatrics), Upazilla Health Complex, Keranigonj, Dhaka, Bangladesh
\end{abstract}

[Received: 17 October 2019; Accepted: 12 November 2019; Published: 1 December 2019]

\begin{abstract}
Background: Post-operative infection can occur after bone grafting among patietns with jaw cyst. Objective: The purpose of the present study was to compare the rate of infection as postoperative outcomes after hydroxyapatite and allogenic bone graft among jaw cyst patients. Methodology: This randomized clinical trial was conducted in the Department of Oral and Maxillofacial Surgery at Bangabandhu Sheikh Mujib Medical University, Dhaka, Bangladesh from July 2006 to June 2008. Patients presented with radicular and dentigerous cyst and relatively non infected cystic lesion were selected as study population. The study population were divided into two groups designed as Group A treated with with allogenic-bone graft and Group B treated with hydroxyapatite alloplastic material after enucleation of the cystic lesion. The rate of infection was recorded after surgery in both group A and B. Result: A total number of 28 patients were recruited for this study of which 14 patients were treated with hydroxyapatite crystals bone graft in group A and 14 patients were treated with allogenic bone graft in group B. Post-operative infection was not found in group A and $5(35.7 \%)$ in group B $(\mathrm{p}<0.05)$. Infection occurred in $1(20.0 \%)$ case in one side intact and 4(80.0\%) in both side lost. Infection was found in $1(20.0 \%)$ case and $4(80.0 \%)$ cases in average and poor oral hygiene status respectively. Conclusion: In conclusion more infection occurs in allogenic bone graft group than the group treated with hydroxyapatite alloplastic material. [Bangladesh Journal of Infectious Diseases, December 2019; 6(2):29-33]
\end{abstract}

Keywords: Comparison; Rate of Infection; Hydroxyapatite; Allogenic Bone Graft; Jaw Cyst

Correspondence: Dr. Showkat Mamun, Assistant Professor, Department of Oral and Maxillofacial Surgery, Dhaka Dental College and Hospital, Mirpur 14, Dhaka, Bangladesh; Email: mamunshowkat@ gmail.com; Cell no.: +8801715025367

Conflict of interest: There is no conflict of interest to any of the authors of this article.

Funding agency: The study was not funded by any authority.

Contribution to authors: Mamun S, Haider IA, Nasiruddin involved in protocol preparation, data collection and literature search up to manuscript writing. Rahman T, Islam SMJ, Diba F involved in preparation and revision of this manuscript.

How to cite this article: Mamun S, Haider IA, Nasiruddin, Rahman T, Islam SMJ, Diba F. Comparison of Rate of Infection during Hydroxyapatite and Allogenic Bone Graft Used In Jaw Cyst: A Randomized Clinical Trial. Bangladesh J Infect Dis 2019;6(2):29-33

Copyright: (02019. Mamun et al. Published by Bangladesh Journal of Infectious Diseases. This article is published under the Creative Commons CC BY-NC License (https://creativecommons.org/licenses/by-nc/4.0/). This license permits use, distribution and reproduction in any medium, provided the original work is properly cited, and is not used for commercial purposes. 


\section{Introduction}

Jaw cyst is frequently encounter during maxillofacial surgery ${ }^{1}$. However, radicular cyst is the most common type of inflammatory odontogenic cysts of the jaws, which comprises nearly $65 \%$ to $70 \%$ of all jaw cysts and dentigerous cyst is the most common type of developmental odontogenic cyst of the jaw which is nearly $15 \%$ to $18 \%$ of all jaw cysts ${ }^{2}$. Following enucleation of a cyst defects smaller than two or bellow two $\mathrm{cm}$ in diameter can be closed primarily and normally fill up with blood clot. However, in case of large defect, infection are more likely to occur in a large haematoma due to breakdown of $\operatorname{clot}^{3}$. Therefore, it is considered as good technique to obliterate the dead space of a sizable defect by packing the cavity with bone or a bone substitute. In the large surgical cavity, residual contour defects due to collapse of soft tissue into the cavity can be eliminated and the repair process appears clinically and roentgenographically to proceed more rapidly than after simple surgical excision ${ }^{4}$ (Marble 1968).

Several cementing materials has been used to reconstruct defects of the jaw and other facial bones, to obliterate mastoidectomy cavities, and to reconstruct the ossicular chain and wall of the outer ear canal ${ }^{5}$. Hydroxyapatite is one of them. There are several use of hydroxyapatite and the uses of Hydroxyapatite ranges from augmenting atrophic alveolar ridges to repairing long-bone defects, ununited fractures, middle ear prostheses, spinal fusions, and cranioplasties ${ }^{6}$.

Spinal fusion presents opportunities for the use of bioceramics in addition to cranioplasty ${ }^{7}$. Koyama and $\mathrm{Handa}^{8}$ used porous hydroxyapatite beads in patients undergoing cervical laminoplasty for stenosis. Sixty patients underwent surgery; the anteroposterior diameter of the spinal canal was enlarged and maintained by the interposition of the HA beads between the cut laminal surfaces. There were no complications from the implants. In a study it has been reported 144 solitary bone cysts treated by curettage and packing with freeze-dried crushed cortical-bone allograft of which 108 cases have been healed primarily. However, 98 cases have been healed primarily and completely and 10 cases have been healed with a small, static, nonprogressive residual defect, for an over-all rate of healing of $75.0 \%$ cases without any infection.

In another study ${ }^{9}$, unilocular bone cyst cases are treated with curettage followed by bone graft and excellent results are found in majority cases, where patients are treated with autogenous bone graft with few cases of infection. This present study was undertaken to compare the rate of infection as postoperative outcomes after hydroxyapatite and allogenic bone graft among jaw cyst patients.

\section{Methodology}

Study Population and Settings: This single centre, parallel, randomized clinical trial was conducted in the Department of Oral and Maxillofacial Surgery at Bangabandhu Sheikh Mujib Medical University, Dhaka, Bangladesh from July 2006 to June 2008 for a period of two (02) years. Patients presented with radicular and dentigerous cyst with the size of the lesion between $2 \mathrm{~cm}$ to $7 \mathrm{~cm}$. in diameter and relatively non infected cystic lesion were selected as study population. Patients with any systemic bone disease or patients with comorbidities like diabetes mellitus, tuberculosis, rheumatic heart diseases and renal failure patients or patients who had taken radiotherapy in the orofacial region were excluded from this study. Written informed consent was taken from the patient or legal guardian. Permission for the study was taken from the concerned department of BSMMU.

Randomization and Blinding: Patients were included in the study after the clinical and radiological evaluation. The computer generated simple random sampling technique was applied to divide the study population into two groups.

Allocation: The half of total cases were treated with allogenic-bone graft and rest half cases were treated hydroxyapatite alloplastic material after enucleation of the cystic lesion. Medical grade Hydroxyapatite was prepared according to manufacturer instructions. The powders was sterilized by applying a Co60 gamma-ray radiation at the dosage of 2.5 MRad. Lyophilized radiation sterilized bone allograft supplied by Tissue Bank and Biomaterial Research unit, Atomic Energy Research Establishment, Savar, Institute of Food and radiation biology, Bangladesh Atomic Energy Commission, Savar, Dhaka. Sterilization of tissues by ${ }^{60} \mathrm{CO}$ Gamma Radiation to destroy or inactivate or reduces the microorganism to a Sterility Assurance Level (SAL) of $10^{-6}$. Preoperatively routine blood test, random blood sugar (RBS), serum urea, creatinine, serum alkaline phosphatase, serum calcium level, and radiological examination in all cases were done.

Surgical procedure: The standard surgical procedure was to be performed meticulously in sterile environment under local anesthesia and 
sedation. Enucleation of cyst was done with removal of all granulation tissue. After enucleation of cyst bony cavity was irrigated with diluted povidone iodine for the purpose of debridment. Granules of hydroxyapatite or allobone was placed on the surgical defect and wetted with patient blood or saline solution followed by primary closure of the wound. Prophylactic antibiotics like Cephradine $500 \mathrm{mg} 8$ hourly continued for 7 days, Metronidazole $400 \mathrm{mg}$ three times daily for 5 to 7 days, analgesics like NSAID and mouthwash was prescribed.

Statistical Analysis: All the data sheet of history and $\mathrm{x}$-ray were collected and were analyzed scientifically. Computer based statistical analysis was carried out with appropriate techniques and systems. Chi-square test was done to find out association between different variables and ' $t$ ' test was done for comparing outcome scores between the treatment groups. Level of significance was set at $\mathrm{P}<0.05$.

Follow Up and Outcome Measures: The wound was checked on the following day for sign of infection. Sutures were removed on seventh postoperative day. Radiographs for each patient was done from the same diagnostic center with the same machine and the operator.

\section{Result}

A total number of 28 patients were recruited for this study of which 14 patients were treated with hydroxyapatite crystals bone graft in group A and 14 patients were treated with allogenic bone graft in group B. Follow-up data were collected after 1, 3 and 6 months of bone graft. The age of patients of both groups ranged between 14 and 58 years. In group A, the highest number of patients was in the age group 31 to 40 years; and in group $\mathrm{B}$, the highest number of patients was in the age group of 21 to 30 years (Table 1 ).

Table 1: Distribution of patients of both groups by age

\begin{tabular}{|l|c|c|}
\hline Age Group & Group A & Group B \\
\hline Up to 20 Years & $4(28.6 \%)$ & $4(28.6 \%)$ \\
\hline 21 to 30 Years & $3(21.4 \%)$ & $7(50.0 \%)$ \\
\hline 31 to 40 Years & $5(35.7 \%)$ & $2(14.3 \%)$ \\
\hline More than 40 Years & $2(14.3 \%)$ & $1(7.1 \%)$ \\
\hline Total & $\mathbf{1 4}(\mathbf{1 0 0 . 0 \%})$ & $\mathbf{1 4 ( 1 0 0 . 0 \% )}$ \\
\hline
\end{tabular}

Group-A: With Hydroxyapatite bone graft; Group-B: With Allogenic bone graft
Post-operative infection was not found in group A and $5(35.7 \%)$ in group B and the difference was statistically significant $(\mathrm{p}<0.05)$.

Table 2: Distribution of the patients by management type and incidence of infection.

\begin{tabular}{|l|l|l|l|}
\hline $\begin{array}{l}\text { Post- } \\
\text { Operative } \\
\text { Infection }\end{array}$ & \multicolumn{1}{|c|}{ Group A } & Group B & $\begin{array}{c}\text { P } \\
\text { value }\end{array}$ \\
\hline Infection occur & $0(0.0 \%)$ & $5(35.7 \%)$ & 0.020 \\
\cline { 1 - 2 } No infection & $14(100.0 \%)$ & $9(64.3 \%)$ & \\
\cline { 1 - 3 } Total & $\mathbf{1 4}(\mathbf{1 0 0 . 0 \% )})$ & $\mathbf{1 4}(\mathbf{1 0 0 . 0 \% )}$ & \\
\hline
\end{tabular}

Group-A: With Hydroxyapatite bone graft; Group-B: With Allogenic bone graft; $\mathrm{S}=$ Significant; $\mathrm{P}$ value reached from $\mathrm{Chi}$ square test

Infection occurred in $1(20.0 \%)$ case in one side intact and 4(80.0\%) in both side lost. No infection occurred in $20(87.0 \%$ ) in one side intact and $3(13.0 \%)$ in both side lost (Table 3).

Table 3: Comparison of Incidence of Infection with Cortical Bone Erosion

\begin{tabular}{|l|c|c|c|}
\hline \multirow{2}{*}{$\begin{array}{l}\text { Cortical } \\
\text { Bone }\end{array}$} & \multicolumn{2}{|c|}{ Infection } & \multirow{2}{*}{$\begin{array}{c}\text { P } \\
\text { value }\end{array}$} \\
\cline { 2 - 3 } & Present & Absent & \\
\hline $\begin{array}{l}\text { One side } \\
\text { intact }\end{array}$ & $1(20.0 \%)$ & $20(87.0 \%)$ & \\
\hline Both side lost & $4(80.0 \%)$ & $3(13.0 \%)$ & \multirow{2}{*}{0.001} \\
\hline Total & $\mathbf{5 ( 1 0 0 . 0 \% )}$ & $\mathbf{2 3}(\mathbf{1 0 0 . 0 \%})$ & \\
\hline
\end{tabular}

Infection was found in $1(20.0 \%)$ case and $4(80.0 \%)$ cases in average and poor oral hygiene status respectively. No infection was occurred in 4(17.4\%) cases, $10(43.5 \%)$ cases, $8(34.8 \%)$ cases and $1(4.3 \%)$ case in excellent, good, average and poor oral hygiene status respectively (Table 4).

Table 4: Association of Oral Hygiene status and Infection among the Study Population

\begin{tabular}{|l|c|c|c|}
\hline \multirow{2}{*}{$\begin{array}{l}\text { Oral } \\
\text { Hygiene }\end{array}$} & \multicolumn{2}{|c|}{ Infection } & \multirow{2}{*}{$\begin{array}{c}\text { P } \\
\text { value }\end{array}$} \\
\cline { 2 - 3 } & Present & Absent & \\
\hline Excellent & $0(0.0 \%)$ & $4(17.4 \%)$ & \\
\hline Good & $0(0.0 \%)$ & $10(43.5 \%)$ & \multirow{2}{*}{0.000} \\
\hline Average & $1(20.0 \%)$ & $8(34.8 \%)$ & \\
\hline Poor & $4(80.0 \%)$ & $1(4.3 \%)$ & \\
\hline Total & $\mathbf{5 ( 1 0 0 . 0 \% )}$ & $\mathbf{2 3 ( 1 0 0 . 0 \% )}$ & \\
\hline
\end{tabular}

Infection occurred in $1(20.0 \%)$ in maxilla and $4(80.0 \%)$ in mandible. No infection was found in $18(78.3 \%)$ in maxilla and $5(21.7 \%)$ in mandible. Statistical significant $(\mathrm{p}<0.05)$ difference was found between the groups (Table 5). 
Table 5: Distribution of Patients by Site of Lesion and Incidence of Infection

\begin{tabular}{|c|c|c|c|}
\hline \multirow{2}{*}{$\begin{array}{l}\text { Site of } \\
\text { Lesion }\end{array}$} & \multicolumn{2}{|c|}{ Infection } & \multirow[t]{2}{*}{$P$ value } \\
\hline & Present & Absent & \\
\hline Maxilla & $1(20.0 \%)$ & 18(78.3\%) & \multirow{3}{*}{$0.026^{\mathrm{S}}$} \\
\hline Mandible & $4(80.0 \%)$ & $5(21.7 \%)$ & \\
\hline Total & $5(100.0 \%)$ & $23(100.0 \%)$ & \\
\hline
\end{tabular}

$\mathrm{NS}=$ Not significant; $\mathrm{P}$ value reached from Chi square test

\section{Discussion}

One of the major factors determining the quality of bone graft substitutes is the speed with which the graft material integrates into the host bone with the less chance of infection. It is difficult to compare the rate of graft incorporation reported in various studies $^{8-10}$, as no quantitative measures are available for evaluation of bone ingrowth into porous material. Histological analysis could provide such information, however, appears impractical, due to the requirement of bone biopsies unless performed during associated procedures ${ }^{11}$. Hence radiological assessment has been widely accepted as the method of choice, however, standardized assessment guidelines have not been defined.

In this present study 28 patients are included after the clinical and radiological evaluation where 14 cases are treated with allogenic-bone graft and the rest 14 cases are treated with hydroxyapatite alloplastic-bone graft material after enucleation of the cystic lesion.

Infection is occurred $1(20.0 \%)$ and $4(80.0 \%)$ in average and poor oral hygiene status. No infection is found in $4(17.4 \%)$ cases in excellent, $10(43.5 \%)$ cases in good, and $8(34.8 \%)$ cases in average and 1 $(4.3 \%)$ case in poor oral hygiene status. Therefore it can be postulated that poor oral hygiene contributes to infection of the graft.

Post-operative infection is not found in hydroxyapatite bone graft group and 5(35.7\%) cases in allogenic bone graft group and the difference is statistically significant $(\mathrm{p}<0.05)$. Infection occurred in $1(20.0 \%)$ in maxilla and $4(80.0 \%)$ in mandible. This result indicates that hydroxyapatite bone graft is better than allogenic bone graft considering the rate of infection after operation. This findings is consistent with the other studies $^{12-14}$.

Infection is occurred in $1(20.0 \%)$ case in one side intact and $4(80.0 \%)$ cases in both side lost in allogenic bone graft group. No infection is occurred in $20(87.0 \%)$ cases in one side intact and 3(13.0\%) cases in both side lost. Statistical significant $(\mathrm{p}<0.05)$ difference is found. This study relatively correlates with King et $\mathrm{al}^{15}$ as well as Norman and Paul $^{16}$.

The infection was remarkably less in the hydroxyapatite group because of its fine granular structure which contributed to very reduce anatomical dead space than that of the allografts which had larger particles which contributed to infection. After placement of hydroxyapatite as a graft it solidifies and work as single unit of osseointegrated structure that also contributes to less infection than the allo group which is supported by the findings of Putzier et $\mathrm{al}^{17}$. Infection has occurred usually within the one week after operation and is presented by the features of localized swelling and exudation which leads to exposure of grafted materials. This condition is then treated by removal of the graft material and curettage of necrosed tissue and use of proper antibiotics.

The allograft group is more infected than the hydroxyapatite graft group and may be due to loss of biological properties secondary to its processing which is supported by Friedlander 1983. Other reasons for this inconsistency include variable donor age with material from older donors being less osteoinductive, how carefully the material is processed, the level of residual calcium and the final particle size of the prepared graft reported by Schwartz and coworkers.

\section{Conclusion}

In conclusion none of the patient of the hydroxyapatite group is infected. This safe and osteoconductive HA appears suitable for filling bone defects and bone cavities, showing resorption and a rapid osseous integration without infection when it has been compared with allogenic bone graft. A large scale study should be conducted to get the real scenario.

\section{References}

1. Aho AJ, Hirn M, Aro HT, Heikkilä JT, Meurman O 1998, 'Bone bank service in Finland. Experience of bacteriologic, serologic and clinical results of the Turku Bone Bank 19721995', Acta Orthop Scand, vol. 69, pp. 559-565.

2. Bodner L. Cystic lesions of the jaws in children. International journal of pediatric otorhinolaryngology. 2002 Jan $11 ; 62(1): 25-9$.

3. Gardner DG, Kessler HP, Morency R, Schaffner DL. The glandular odontogenic cyst: an apparent entity. J Oral Pathol. 1988;17:359-366 
4. Kattimani VS, Chakravarthi PS, Kanumuru NR, Subbarao VV, Sidharthan A, Kumar TS, Prasad LK. Eggshell derived hydroxyapatite as bone graft substitute in the healing of maxillary cystic bone defects: a preliminary report. Journal of international oral health: JIOH. 2014;6(3):15.

5. Shear M, Speight PM. Cysts of the oral and maxillofacial regions. Munksgaard: Blackwell; 2007

6. Bodner L, Manor E, Shear M, Waal I. Primary intraosseous squamous cell carcinoma arising in an odontogenic cyst: a clinicopathologic analysis of 116 reported cases. J Pathol Med. 2011;10:733-738

7. Ramer M, Valauri D. Multicystic lateral periodontal cyst and botryoid odontogenic cyst. Multifactorial analysis of previously unreported series and review of the literature. New York State Dent J. 2005;71:47-51

8. Stoelinga PJW, Bronkhorst FB. The incidence, multiple presentation and recurrence of aggressive cysts of the jaws. J Craniomaxillofac Surg. 1988;16:184-195

9. Kaplan I, Anavi Y, Hirshberg A. Glandular odontogenic cyst: a challenge in diagnosis and treatment. Oral Dis. 2007; $14: 575-581$

10. vanHeerden WFP, Raubenheimer EJ, Turner ML . Glandular odontogenic cyst. Head Neck 1992;14:316-320

11. Rosenstein T, Pogrel MA, Smith RA, Regezi JA. Cystic ameloblastoma-behavior and treatment. J. Oral and Maxillofac Surg 2001; 59;1311-1316
12. Lau SK, Tideman H, Wu PC. Ameloblastic carcinoma of the jaws. A report of two cases. Oral Surg Oral Med Oral Pathol Oral Radiol Endod 1998;85: 78-81

13. Stoelinga PJ, Bronkhorst FB. The incidence, multiple presentation and recurrence of aggressive cysts of the jaws. Journal of Cranio-Maxillofacial Surgery. 1988;16:184-95

14. Regezi JA. Odontogenic cysts, odontogenic tumors, fibroosseous, and giant cell lesions of the jaws. Modern pathology. 2002;15(3):331-41

15. King AA, McKinstry RC, Wu J, Eapen M, Abel R, Varughese T, Kamani N, Shenoy S. Functional and radiologic assessment of the brain after reduced-intensity unrelated donor transplantation for severe sickle cell disease: Blood and Marrow Transplant Clinical Trials Network Study 0601. Biology of Blood and Marrow Transplantation. 2019;25(5):e174-8

16. Wood NK, Goaz PW. Differential Diagnosis of Oral and Maxillofacial Lesions (Fifth edition), Mosby Publication, 1997;263

17. Putzier M, Strube P, Funk JF, Gross C, Mönig HJ, Perka C, Pruss A. Allogenic versus autologous cancellous bone in lumbar segmental spondylodesis: a randomized prospective study. European Spine Journal. 2009;18(5):687-95

18. Friedlaender GE. Immune responses to osteochondral allografts. Current knowledge and future directions. Clinical orthopaedics and related research. 1983;174:58-68 